\title{
Various Techniques for De-noise Image
}

\author{
Asma Abdulelah Abdulrahman, Mohammed Rasheed", Suha Shihab
}

Applied Science Department, University of Technology, Baghdad, Iraq. E-mail: rasheed.mohammed40@yahoo.com

Abstract: Wavelet decomposition has a great role in eliminating noise, the aim of this work on different noise removal techniques by analyzing the color image. Based on the analysis of different image compression techniques, this paper provides a survey of existing research papers. Different types of method for noise are analyzed from the necessary image, where the disturbance was removed using wavelets with basic theories, and the most important details that will be presented in this work, which clarifies the proposed smooth and effective theory in terms of accuracy in our results. By creating new algorithms that explain how to use the proposed theory, some medical applications were used Discrete Wavelet Transform (DWT) where the results were satisfactory obtained, our proposed theory has been proven to be effective, and examples used will demonstrated this method.

Keywords: De-noise Image; Threshold; Soft Threshold; Hard Threshold; Wavelet Transform

\section{Introduction}

Wavelets have taken a wide role in many fields of science and engineering in solving many numerical problems, for example integral equations, voltera and fredholm, integro differential equation variational problems etc ${ }^{[1-8]}$. One of the most important applications of wavelets in the field of images is to de- noise and compression $^{[6,7]}$, in this work. Wavelets are applied to De-noise from the image and different theories, and an example was used. The fingerprint, which obtained good results, that proves the important role of wavelets in image processing, especially medical pictures ${ }^{[6]}$.

$\Psi_{\mathrm{a}, \mathrm{b}}(\mathrm{t})=|\mathrm{a}|^{\frac{1}{2}} \Psi\left(\frac{\mathrm{t}-\mathrm{b}}{\mathrm{a}}\right) \quad \mathrm{a}, \mathrm{b} \in \mathrm{R} \quad \mathrm{a} \neq 0$
where: $\Psi(\mathrm{t})=\left[\Psi_{0}(\mathrm{t}), \Psi_{1}(\mathrm{t}), \ldots, \Psi_{\mathrm{M}-1}(\mathrm{t})\right]^{\mathrm{T}}$

The elements $\Psi_{0}(\mathrm{t}), \Psi_{1}(\mathrm{t}), \ldots, \Psi_{\mathrm{M}-1}(\mathrm{t})$ are the basis functions, orthogonal on the $[0,1]$ the color image I in size $256 \times 256$ analyses image to approximation coefficients and details coefficients select threshold will be see all details in section 2 and the results in Table 1 and 2. In addition, it took an important role in the field of image processing technology with the help of contractions and expansions of the mother waves that are responsible for the coefficients a and $\mathrm{b}$. It divides the color image in to bands according to the level where the image is analyzed by the wavelet filter, which analyzes the image to the coefficients of approximation and details ${ }^{[8]}$. There are several methods can be used to enhance any image by mathematical equations which can be used as a filter and coefficients, the images and methods can be used with image processing illustrated in ${ }^{[10-85]}$.

\section{De-noising image methods}

Wavelet thresholding technique is used in this work influenced by the wavelet coefficient. So that each

Copyright (C) 2020 Asma Abdulelah Abdulrahman et al.

doi: 10.18686/esta.v7i4.127

This is an open-access article distributed under the terms of the Creative Commons Attribution Non-Commercial License (http://creativecommons.org/licenses/by-nc/4.0/), which permits unrestricted non-commercial use, distribution, and reproduction in any medium, provided the original work is properly cited. 
parameter is a threshold with the threshold of the image if the coefficient is smaller than the threshold it will be equal to zero. This which leads to all small transactions equal to zero and for rebuilding and after replacing the small transactions with zero wavelets inverse repeating the image with less noise can be summed up in three steps; constructed discrete wavelets, set the threshold and inverse of discrete wavelet. Figure 1 shows the steps of De-noise image operation.

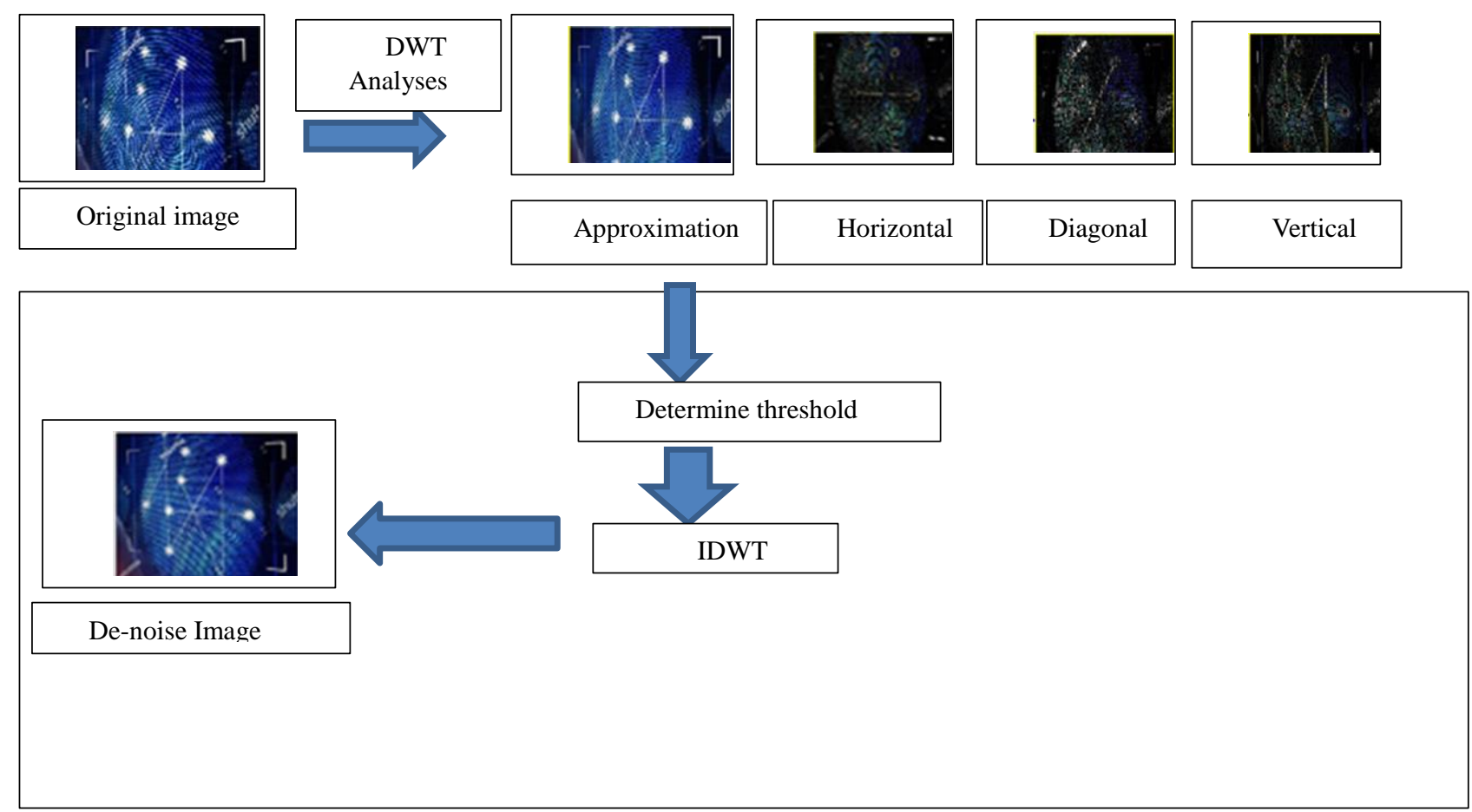

Figure 1. The steps of De-noise image operation.

The methods of threshold with discrete wavelets

\section{Fixed form soft threshold}

2. Penalize high hard threshold

3. Penalize medium hard threshold

4. Penalize low hard threshold

5. Bal-sparsity-norm (sqrt) soft threshold

Table 1. The threshold of each method

\begin{tabular}{|l|l|l|l|}
\hline Number of method & method of De-noising image & Level 1 & Level 2 \\
\hline 1 & Fixed form soft threshold & 4.797 & 4.499 \\
\hline 2 & Penalize high hard threshold & 28 & 28 \\
\hline 3 & Penalize medium hard threshold & 16.25 & 16.25 \\
\hline 4 & Penalize low hard threshold & 14 & 14 \\
\hline 5 & Bal- sparsity-norm (sqrt) soft threshold & 10.56 & 10.56 \\
\hline
\end{tabular}

The table shows the threshold set for each proposed method.

The remnants of the process for each method above with the recording of criteria that show which of the methods that lead to obtaining the best result from raising the noise from the image in Table 2. 
Table 2. Result from raising the noise

\begin{tabular}{|l|l|l|l|l|}
\hline No & Method of De-noising Image & L1 norm & L2 norm & $\begin{array}{l}\text { Max } \\
\text { Norm }\end{array}$ \\
\hline 1 & Fixed form soft threshold & 6.966 & 1478 & 6 \\
\hline 2 & Penalize high hard threshold & 1.352 & 3055 & 32 \\
\hline 3 & Penalize medium hard threshold & 7.287 & 1711 & 18 \\
\hline 4 & Penalize low hard threshold & 6.061 & 1439 & 15 \\
\hline 5 & Bal- sparsity-norm (sqrt) soft threshold & 1.464 & 3022 & 13 \\
\hline
\end{tabular}

\subsection{Threshold methods}

Figure 2 shows the levels of threshold in every De-noise method with their residue.

\begin{tabular}{lll}
\hline No method of De-noising image & Residuals & De-noise image
\end{tabular}

$1 \quad$ Fixed form soft threshold

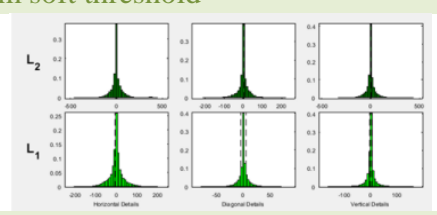

Penalize high hard threshold

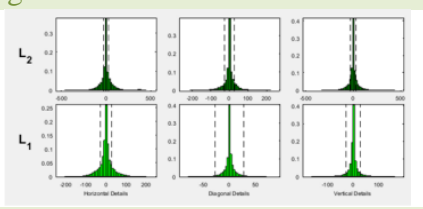

Penalize medium hard threshold

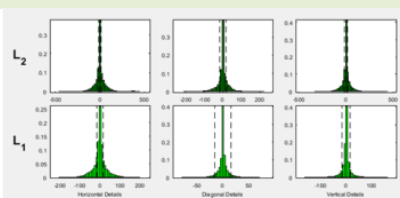

Penalize low hard threshold

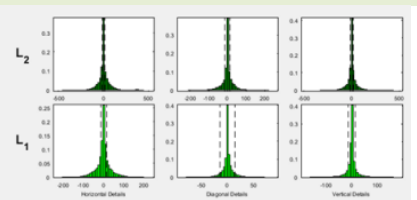

Bal- sparsity-norm (sqrt) soft threshold

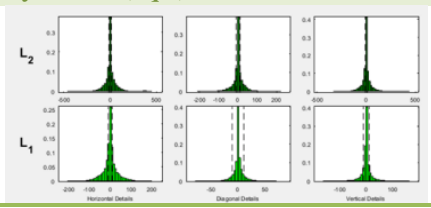

5
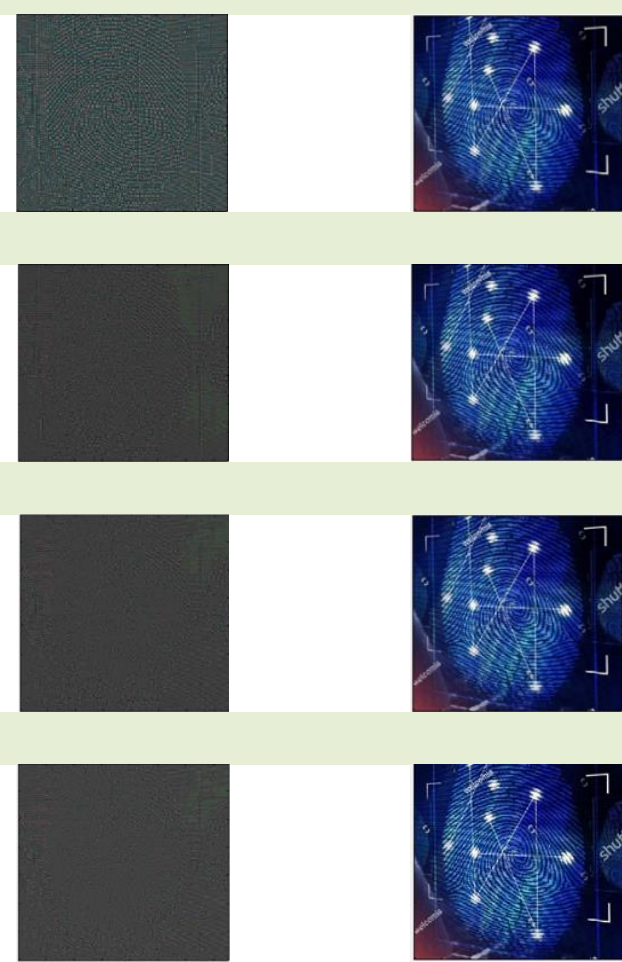

Figure 2. The threshold stages for each method with the waste and the result of raising the noise.

\section{Conclusion}

The aim of this work is on various noise removal techniques by analyzing the color image. Based on an analysis of different image compression techniques, this paper provides a survey of existing research papers. Different types of noise methods are analyzed from the necessary image, where the disturbance was removed using waves with basic theories and the most important details that will be presented in this work, which clarifies the 
proposed smooth and effective theory in terms of accuracy in our results. By creating new algorithms that explain how to use the proposed theory, some medical applications have used separate wave transformation (DWT) where satisfactory results have been obtained and our proposed theory has proven effective, and the example that has been applied has proven the power and role of wavelets in image processing.

\section{References}

1. Yang C, Hou J. Chebyshev wavelets method for solving Bratu's problem. Boundary Value Problem 2013; 2013: 142 .

2. Fariborzi AMA, Daliri S, Bahmanpour M. Numerical solution of integro-differential equation by using chebyshev wavelets operational matrix of integration. International Journal of Mathematical Modelling \& Computations 2012; 2(2): 127-136.

3. Ali A, Iqbal MA, Mohyud-Din ST. Chebyshev wavelets method for delay differential equations. International Journal of Modern Mathematical Sciences 2013; 8(2): 102-110.

4. Abd-Elhameed WM, Doha EH, Youssri YH. New spectral second kind chebyshev wavelets algorithm for solving linear and nonlinear second-order differential equations involving singular and Bratu type equations. Abstract and Applied Analysis 2013; 2013.

5. Biazar J, Ebrahimi H. A strong method for solving systems of integro-differential equations. Applied Mathematics 2011; 2(9): 1105-1113.

6. Julius A. Medical image compression by using discrete haar wavelet transform. International Journal of Science and Research 2016; 5(9): 1196-1200.

7. Awad A, Sadiq A. DCWT: Image compression method based on wavelet and DCT transforms. Journal of Baghdad College of Economic Sciences University 2012; (32): 328-338.

8. Satyanarayana B, Abdulelah A. Application of the discrete laguerre wavelet transform. International Journal of Engineering \& Technology 2018; 7(3): $1-5$.

9. Satyanarayana B, Abdulrahman AA, Kumar YP. Image processing by using Discrete Laguerre Wavelets Transform (DLWT). International Journal of Computer Applications 2017; 171(7).

10. Shihab SN, Sarhan MA. Convergence analysis of shifted fourth kind Chebyshev wavelets. IOSR Journal of Mathematics 2014; 10(2): 54-58.

11. Al-Rawi SN. Numerical solution of integral equations using Taylor series. Journal of the College of Education 1998; 5: 51-60.

12. Shihab SN, Naif TN. On orthonormal Bernstein polynomial of order eight. Open Science Journal of Mathematics and Application 2014; 2(2): 15-19.

13. Delphi M, Shihab S. State parametrization basic spline functions for trajectory optimization. The Journal of Natural Sciences, Life and Applied Sciences 2019; 3(4): 110-119.

14. Delphi M, Shihab S. Modified basic spline, multiscaling and wavelets algorithms for optimal control problems [master's thesis]. Iraq: University of Technology; 2019.

15. Shihab SN, Naif TN. Direct methods based on orthonormal Bernstein polynomials for solving optimal control problems [master's thesis]. Iraq: University of Technology; 2014.

16. Shihab SN, Sarhan MA. Numerical solution of variational calculus using chebyshev wavelets method [PhD thesis]. Iraq: University of Technology; 2015.

17. Shihab SN, Falah AH. Efficient numerical algorithms for the optimal control problem [master's thesis]. Iraq: University of Technology; 2008.

18. Shihab SN, Al-Janabi ASAR. On the numerical solution for solving some continuous optimal control problems [PhD thesis]. Iraq: Al-Mustansiriyah University; 2005.

19. Al-Faour O, Shihab SN, Al-Saleni BF. Multistep methods for solving nonlinear integral equations. Journal of the College of Basic Education 2001; 12(2).

20. Al-Faour O, Shihab SN, Al-Nasser RH. Expansion method for solving volterra equations. Journal of Babylon University 2000; 7(3): 1355-1362.

21. Al-Faour O, Al-Ani FID, Al-Rawi SN. Numerical evaluation of fourier transformation using orthogonal functions. Engineering and Technology Journal 2000; 17(7).

22. Al-Ani FID, Al-Faour O, Al-Rawi SN. Numerical solution of variational calculus using chebyshev wavelet method. Journal of Al-rafidain University 1997; 2: 1-10.

23. Shihab S, Delphi M. Direct iterative algorithm for solving optimal control problems using B-Spline polynomials. Emirates Journal for Engineering Research 2019; 24(4): 1-9.

24. Alrawy SS, Salih AA. Shifted modified chebyshev direct method for solving quadratic optimal control problem. Samarra Journal of Pure and Applied Science 2020; 2(1): 67-75.

25. Shihab S, Ali HA, Kasheem BE. Legendre wavelets method for solving boundary value problems. Journal of the College of Basic Education 2012; 18(76): 73-86.

26. Shihab SN, Asmaa AA, Ali MNM. Collocation orthonormal Bernstein polynomials method for solving integral equations. Engineering and Technology Journal 2015; 33(8 Part (B)): 1493-1502.

27. Delphi M, Shihab S. Modified iterative algorithm for solving optimal control problems. Open Science Journal of Statistics and Application 2019; 6(2): 20-27.

28. Al-Rawi SN. On the solution of certain fractional integral equations. Journal of Kirkuk University Scientific Studies 2006; 1(2).

29. Shihab SN, Abdalrehman AA. Numerical solution 
of calculus of variations by using the second chebyshev wavelets. Engineering and Technology Journal 2012; 30(18): 3219-3229.

30. Shihab SN, Abdelrehman AA. Some new relationships between the derivatives of first and second chebyshev wavelets. International Journal of Engineering, Business and Enterprise Applications 2012.

31. Shehab SN, Ali HA, Yaseen HM. Least squares method for solving integral equations with multiple time lags. Engineering and Technology Journal 2010; 28(10): 1893-1899.

32. Shihab SN, Abdalrehman AA. Solving optimal control linear systems by using new third kind chebyshev wavelets operational matrix of derivative. Baghdad Science Journal 2014; 11(2): 229-234.

33. Delphi M, Shihab S. Operational matrix basic spline wavelets of derivative for linear optimal control problem. Electronics Science Technology and Application 2019; 6(2): 18-24.

34. Shihab SN, Sarhan MA. New operational matrices of shifted fourth chebyshev wavelets. Elixir International Journal-Applied Mathematics 2014; 69: 23239-23244.

35. Rasheed MS. Study of the effects of acidic solutions on the physical properties of polymeric materials superimposed. Al-Mustansiriyah Journal of Science 2012; 13(49): 6.

36. Rasheed MS, Mahde HS. Electronic combination lock design using remote control. Journal of the College of Basic Education 2012; 18(75): 265-280.

37. Rasheed MS, Mohammed AN. Design of a laser based free space communication system: Laser, optical communication, free space. LAP LAMBERT Academic Publishing 2012.

38. Rasheed MS. Approximate solutions of barker equation in parabolic orbits. Engineering and Technology Journal 2010; 28(3): 492-499.

39. Rasheed MS. An improved algorithm for the solution of Kepler's equation for an elliptical orbit. Engineering and Technology Journal 2010; 28(7): 1316-1320.

40. Rasheed MS. Acceleration of predictor-corrector Halley method in astrophysics application. International Journal of Emerging Technologies in Computational and Applied Sciences 2012; 1(2): 91-94.

41. Rasheed MS. A fast procedure for solving two-body problem in celestial mechanic. International Journal of Engineering, Business and Enterprise Applications 2012; 1(2): 60-63.

42. Rasheed MS. Solve the position to time equation for an object travelling on a parabolic orbit in celestial mechanics. Diyala Journal for Pure Science 2013; 9(4): 37-47.

43. Rasheed MS. Comparison of starting values for implicit iterative solutions to hyperbolic orbits equation. International Journal of Software and Web Sciences 2012; 1(2): 65-71.

44. Rasheed MS. On solving hyperbolic trajectory using new predictor-corrector quadrature algorithms. Baghdad Science Journal 2014; 11(1): 186-192.
45. Rasheed MS. Modification of three order methods for solving satellite orbital equation in elliptical motion. Journal of University of Anbar for Pure Science 2020; 14(1): 33-37.

46. Rasheed M, Barille R. Room temperature deposition of $\mathrm{ZnO}$ and $\mathrm{Al}: \mathrm{ZnO}$ ultrathin films on glass and PET substrates by DC sputtering technique. Optical and Quantum Electronics 2017; 49(5).

47. Rasheed M, Barille R. Optical constants of DC sputtering derived ITO, $\mathrm{TiO}_{2}$ and $\mathrm{TiO}_{2}: \mathrm{Nb}$ thin films characterized by spectrophotometry and spectroscopic ellipsometry for optoelectronic devices. Journal of Non-Crystalline Solids 2017; 476: 1-14.

48. Rasheed M, Barille R. Comparison the optical properties for $\mathrm{Bi}_{2} \mathrm{O}_{3}$ and $\mathrm{NiO}$ ultrathin films deposited on different substrates by DC sputtering technique for transparent electronics. Journal of Alloys and Compounds 2017; 728: 1186-1198.

49. Saidani T, Zaabat M, Aida MS, et al. Influence of precursor source on sol-gel deposited $\mathrm{ZnO}$ thin films properties. Journal of Materials Science: Materials in Electronics 2017; 28(13): 9252-9257.

50. Boumezoued A, Guergouri K, Barille R, et al. ZnO nanopowders doped with bismuth oxide, from synthesis to electrical application. Journal of Alloys and Compounds 2019; 791: 550-558.

51. Bouras D, Mecif A, Barille R, et al. $\mathrm{Cu}: \mathrm{ZnO}$ deposited on porous ceramic substrates by a simple thermal method for photocatalytic application. Ceramics International 2018; 44(17): 21546-21555.

52. Saidi W, Hfaidh N, Rasheed M, et al. Effect of $\mathrm{B}_{2} \mathrm{O}_{3}$ addition on optical and structural properties of $\mathrm{TiO}_{2}$ as a new blocking layer for multiple dye sensitive solar cell application (DSSC). RSC Advances 2016; 6(73): 68819-68826.

53. Auktuolis A, Girtan M, Mousdis GA, et al. Measurement of charge carrier mobility in perovskite nanowire films by photo-celiv method. Proceedings of the Romanian Academy-Series A: Mathematics, Physics, Technical Sciences, Information Science 2017; 18(1): 34-41.

54. Dkhilalli F, Megdiche S, Guidara K, et al. AC conductivity evolution in bulk and grain boundary response of sodium tungstate $\mathrm{Na}_{2} \mathrm{WO}_{4}$. Ionics 2018; 24(1): 169-180.

55. Dkhilalli F, Borchani SM, Rasheed M, et al. Structural, dielectric, and optical properties of the zinc tungstate $\mathrm{ZnWO}_{4}$ compound. Journal of Materials Science: Materials in Electronics 2018; 29(8): 6297-6307.

56. Dkhilalli F, Borchani SM, Rasheed M, et al. Characterizations and morphology of sodium tungstate particles. Royal Society Open Science 2018; 5(8): 172214.

57. Enneffati M, Louati B, Guidara K, et al. Crystal structure characterization and AC electrical conduction behavior of sodium cadmium orthophosphate. Journal of Materials Science: Materials in Electronics 2018; 29(1): 171-179.

58. Kadri E, Krichen M, Mohammed R, et al. Electrical 
transport mechanisms in amorphous silicon/crystalline silicon germanium heterojunction solar cell: impact of passivation layer in conversion efficiency. Optical and Quantum Electronics 2016; 48(12).

59. Kadri E, Messaoudi O, Krichen M, et al. Optical and electrical properties of $\mathrm{SiGe} / \mathrm{Si}$ solar cell heterostructures: Ellipsometric study. Journal of Alloys and Compounds 2017; 721: 779-783.

60. Kadri E, Dhahri K, Zaafouri A, et al. AC conductivity and dielectric behavior of a $-\mathrm{Si}: \mathrm{H} / \mathrm{c}-\mathrm{Si}_{1-\mathrm{y}} \mathrm{Ge}_{\mathrm{y}}$ $/ \mathrm{p}-\mathrm{Si}$ thin films synthesized by molecular beam epitaxial method. Journal of Alloys and Compounds 2017; 705: 708-713.

61. Azaza NB, Elleuch S, Rasheed $\mathrm{M}$, et al. 3-(p-nitrophenyl) coumarin derivatives: Synthesis, linear and nonlinear optical properties. Optical Materials 2019; 96: 109328.

62. Enneffati M, Rasheed M, Louati B, et al. Morphology, UV-visible and ellipsometric studies of sodium lithium orthovanadate. Optical and Quantum Electronics 2019; 51(9).

63. Rasheed M, Sarhan MA. Solve and implement the main equations of photovoltaic cell parameters using visual studio program. Insight-Mathematics 2019; 1(1): 18-26.

64. Rasheed M, Sarhan MA. Characteristics of solar cell outdoor measurements using fuzzy logic method. Insight-Mathematics 2019; 1(1): 1-8.

65. Rasheed M, Sarhan MA. Measuring the solar cell parameters using fuzzy set technique. Insight-Electronic 2019; 1(1): 1-9.

66. Rasheed M. Linear programming for solving solar cell parameters. Insight-Electronic 2019; 1(1): 1016.

67. Rasheed M. Investigation of solar cell factors using fuzzy set technique. Insight-Electronic 2019; 1(1): 17-23.

68. Rasheed M, Barille R. Development and characterization of single and multilayer thin films for optoelectronics application [PhD thesis]. France: University of Angers; 2017.

69. Rasheed M, Shihab S. Analytical modeling of solar cells. Insight-Electronic 2019; 1(2): 1-9.

70. Rasheed M, Shihab S. Modeling and simulation of solar cell mathematical model parameters determination based on different methods. Insight-Mathematics 2019; 1(1): 1-16.

71. Rasheed M, Shihab S. Parameters estimation for mathematical model of solar cell. Electronics Science Technology and Application 2019; 6(1): 2028.
72. Ouda EH, Shihab S, Rasheed M. Boubaker wavelet functions for solving higher order integro-differential equations. Journal of Southwest Jiaotong University 2020; 55(2).

73. Sarhan MA, Shihab S, Rasheed M. A new boubaker wavelets operational matrix of integration. Journal of Southwest Jiaotong University 2020; 55(2).

74. Abdulrahman AA, Rasheed M, Shihab S. Discrete hermite wavelet filters with prove mathematical aspects. Journal of Southwest Jiaotong University 2020; 55(2).

75. Rasheed M, Abdulrahman AA, Shihab S. Discrete chebyshev wavelet transformation with image processing. Journal of Southwest Jiaotong University 2020; 55(2).

76. Abbas MM, Rasheed M. Solid state reaction synthesis and characterization of aluminum doped titanium dioxide nanomaterials. Journal of Southwest Jiaotong University 2020; 55(2).

77. Sarhan MA, Shihab S, Rasheed M. On the properties of two-dimensional normalized boubaker polynomials. Journal of Southwest Jiaotong University 2020; 55(3).

78. Aziz SH, Rasheed M, Shihab S. New properties of modified second kind chebyshev polynomials. Journal of Southwest Jiaotong University 2020; 55(3).

79. Mitlif RJ, Rasheed M, Shihab S. An optimal algorithm for fuzzy transportation problem. Journal of Southwest Jiaotong University 2020; 55(3).

80. Kashem BE, Ouda EH, Aziz SH, et al. Some results for orthonormal boubaker polynomials with application. Journal of Southwest Jiaotong University 2020; 55(3).

81. Mohammedali MN, Sabri RI, Rasheed M, et al. Some results on G-Normed linear spaces. Journal of Southwest Jiaotong University 2020; 55(3).

82. Sabri RI, Mohammedali MN, Rasheed M, et al. Compactness of soft fuzzy metric space. Journal of Southwest Jiaotong University 2020; 55(3).

83. Rasheed M, Shihab S. Numerical techniques for solving parameters of solar cell. Applied Physics 2020; 3(1): 15-27.

84. Abdulrahman AA, Rasheed M, Shihab S. The role of intermittent wavelets in image analysis. Electronics Science Technology and Application 2020.

85. Rasheed M, Abdulrahman AA, Shihab S. The effect of set partitioning in hierarchical trees with wavelet decomposition levels algorithm for image compression. Electronics Science Technology and Application 2020; 7(3): 40-46. 